\title{
Mapping and characterization of stakeholders in the fodder value chain in Southern Rangelands of Kenya: Understanding their roles, interactions and influences
}

\author{
Erick Ouma Omollo ${ }^{1 *}$, Stanley Odhiambo Jawuoro ${ }^{1}$, Oliver Vivian Wasonga ${ }^{1}$ \\ and Danny Simatele ${ }^{2}$
}

\footnotetext{
1Department of Land Resource Management and Agricultural Technology, University of Nairobi, Kenya. ${ }^{2}$ School of Geography, Archaeology and Environmental Studies, University of the Witwatersrand, South Africa.

*Corresponding author. Email: omolloerick88@gmail.com
}

Copyright (@) 2019 Omollo et al. This article remains permanently open access under the terms of the Creative Commons Attribution License 4.0, which permits unrestricted use, distribution, and reproduction in any medium, provided the original work is properly cited.

Received 18th August, 2019; Accepted 23rd September, 2019

\begin{abstract}
Livestock production is the most important economic activity in Kenya. Land use practice in arid and semiarid lands (ASALs) of Kenya is most affected by droughts, which lead to pasture scarcity. Fodder production has been adopted by communities in ASALs to enhance feed availability and generating alternative source of livelihood. However, the scale of fodder production remains low, with poor markets being key challenge in realizing the economic benefits of fodder production. This study was conducted in Makueni and Kajiado Counties to understand institutional structures and stakeholders together with their roles and influences on fodder production and marketing. The two counties were purposively selected as they were some of the target areas where fodder production practices and technologies had been promoted. Data was collected through NetMap tool for identifying and mapping actors, their roles, influence and interactions along the value chain. NetMaps were subjected to quantitative analysis using Organizational Risk Analysis tool in Social Network Analysis to map, as well as measure relationships and influences of stakeholders and examine their relative positions. Results revealed that various stakeholders play multiple roles along the chain, which determine their position and influence in decision-making. Most influential actors included Kenya Agricultural and Livestock Research Organization (KALRO), NGOs and CBOs - they determine access to information, technical and funding resources and markets; thus, key in upscaling, out-scaling and commercialization of fodder production in the study areas. Working in groups enabled producers to easily access technical support, information and interact with other stakeholders in the chain. Efforts for enhancing fodder production should provide more technical support and capacity building to CBOs due to their centrality and strategic position in the network which make them the main stakeholders.
\end{abstract}

Keywords: Drylands, fodder, Kenya, marketing, NetMap, production.

\section{INTRODUCTION}

Livestock production is one of the major subsectors of agriculture upon which many developing economies in Sub-Sahara Africa depend (Anderson and Masters, 2009; Mapfumo et al., 2013). This is so especially among communities that inhabit arid and semi-arid lands (ASALs) of Sub-Sahara Africa (Macharia et al., 2015; LiDeSA, 2015). However, it is most affected by droughts to which many pastoral communities lose large herds of their livestock and take long time to rebuild the stock after drought period (IPCC, 2014). The main stock including cattle, goats and sheep in such areas have become more vulnerable with high mortalities experienced during extreme droughts, which have become more frequent, longer and severer (Huho and Mugalavai, 2010; IPCC, 
2014; LiDeSA, 2015). The ultimate effect of such situation is the inability of such communities to reliably and sustainably depend on livestock production for their livelihoods. In Kenya, for instance, such severely destructive droughts were experienced between 1999 to 2000,2004 to 2006 and 2008 to 2009 and were marked by massive livestock mortalities and therefore livelihood problems especially among pastoralists and agropastoralists in the country (Huho and Mugalavai, 2010).

For more than three decades, fodder production has been promoted among the pastoral and agro-pastoral communities in Kenya as a promising approach to address perennial livestock feed scarcity (Mnene et al., 1999; Dolan et al., 2004). It has also been aimed at creating alternative source of livelihood for such communities through market-oriented fodder production where such communities do not only produce fodder to feed own livestock but also to sell in order to earn extra income for their households (Manyeki et al., 2015; Lugusa et al., 2016). This has been ultimately aimed at enhancing adaptive capacity of pastoral and agro-pastoral communities to drought and related vagaries affecting their livelihoods. Efforts by various stakeholders particularly the Kenya Agricultural and Livestock Research Organization (KALRO) in terms of research and training has led to significant adoption of various fodder production practice such as reseeding and enclosing of natural pastures to allow regeneration (Mnene et al., 1999; Kidake et al., 2016).

Despite evident adoption of such fodder production practices among the communities in the ASALs of Kenya, it is unfortunate that this has not translated into adequate availability of livestock feed among such livestock dependent communities. A lot of households that have adopted fodder practices harvest quite low amounts of hay and grass seed, indicating the inadequacy (Omollo et al., 2017). Low fodder production level is further reflected by livestock mortalities, which has remained high in the country particularly during droughts. Fodder production, as well as marketing practices are influenced by various stakeholders, institutional and governance structures within which they take place (ASDR, 2017). These structures have direct influences on the access to production inputs, extension and information services, as well as markets for hay and grass seeds. This affects the economic value of fodder production as a strategic approach to promoting adaptation to climate change among the dryland communities in Kenya (Omollo et al., 2018).

It is recognized that the scale of fodder production remains low with a lot of unrealized potential due to unsupportive influences by various stakeholders and institutions (Omollo et al., 2017). Adequate exploitation of these potentials would pronounce fodder production as a leading climate change adaptation strategy for ASAL communities. This requires recognition that fodder production and marketing are two strongly interlinked levels that must be taken into account. These two levels involve chain of events and stakeholders as demonstrated by fodder value chain studies in Baringo (Lugusa et al., 2016) and southern rangelands of Kenya (Omollo et al., 2017). Marketing phase remains a bigger challenge in realizing the economic value of fodder production with minimal profits recorded for the marketed fodder among small holder producers (Omollo et al., 2018). The situation has been attributed to dominance of such markets by unscrupulous and exploitative traders, lack of market information and absence of legal market regulation systems (Lugusa, et al., 2016; Omollo, et al., 2017). The ultimate outcome of this is low commercialization and profitability of fodder production as an adaptation to climate change and associated imbalanced spatial temporal distribution and accessibility of feeds in the country (ASDR, 2017).

Addressing the challenges facing fodder production and improving market access require multidimensional approaches. Collective action has been identified as one such approach that can be used effectively by small-scale producers to enhance their market access, market share and profitability (Sally, 2013; Gyau et al., 2014). In addition, digital platforms are important networking tools that boost access to production and marketing information especially for the small-scale producers (Kiveu and Ofafa, 2013; Mattern and Michael, 2015). Therefore, a combination of the two approaches is likely offer stronger, reliable and lasting solution that will improve the economic benefits of fodder production and marketing in Kenya. These efforts require adequate understanding of the existing institutional structures and stakeholders together with their roles and influences on fodder production and marketing particularly in the drylands of Kenya.

Various studies have documented a lot of knowledge about fodder production and its relevance to livestock production in Kenya. A study by Wairore et al. (2015), for instance, found that households that have embraced enclosures for fodder production have noted improvement in livestock production and management practices, as well as increased availability of feed for livestock during the dry periods. These findings were corroborated by Lugusa et al. (2016) who studied fodder value chain in Baringo County. Moreover, Koech et al. (2016) evaluated six rangeland grasses for fodder production in Tana River County with focus on their nutritional contents, as well as productivity under varied soil moisture content. Information from this study has been insightful in advising households on various grass species to plant under different seasons and climatic conditions (Koech et al., 2016). Much advanced fodder value chain analysis was conducted by Omollo et al. (2017) in Makueni and Kajiado Counties. They found that though many households in such areas have embraced fodder production, they have comparatively obtained less profits from the sale of their 
fodder as more profits are gained by the traders in the marketing chain. They attributed this situation to the fact that fodder production in Kenya remains informal with no structures (Lugusa et al., 2016; Omollo et al., 2017).

Despite all these studies, there is no clear understanding of the stakeholders in the fodder value chain and their roles and influences in the production and marketing chain in Kenya. This has resulted in market failures characterized by too low selling prices, lack of market and market information by the producers (Omollo et al., 2017). This indicates the need to identify key stakeholders and institutions as they influence fodder production and marketing, as an entry point to up-scaling fodder production and its benefits.

\section{METHODOLOGY}

\section{Study area}

This study was carried out in Makueni and Kajiado Counties (Amwata et al., 2015), which are found in arid and semi-arid lands (ASALs) of Kenya (Figure 1). These two Counties were purposively selected for the study as they were some of the target areas where fodder production practices and technologies had been introduced by Kenya Agricultural and Livestock Research Organization (KALRO) through the Agricultural Research Supports Program phase two (ARSP-II) in 1998 (Mnene et al., 1999).

Makueni County is located between Latitudes $1^{\circ} 35^{\prime}$ and $30^{\circ} 00^{\prime} \mathrm{S}$ and Longitudes $37^{\circ} 10^{\prime}$ and $38^{\circ} 30^{\prime} \mathrm{E}$, while Kajiado County is between Longitudes $36^{\circ} 5^{\prime}$ and $37^{\circ} 5^{\prime} \mathrm{E}$ and Latitudes $1^{\circ} 0^{\prime}$ and $3^{\circ} 0^{\prime} \mathrm{S}$ (CBS, 1981). The areas are characterized by highly variable and unpredictable rainfall trends, frequent and severe droughts (Gikaba et al., 2014; Amwata et al., 2015). The two Counties receive annual rainfall ranging from 300 to $1250 \mathrm{~mm}$ (County Government of Makueni, 2013) with long rains from March to May, and short ones from October to December (Gikaba et al., 2014; Amwata et al., 2015). They experience wide variation in temperature 12 to $35^{\circ} \mathrm{C}$, and this is associated with time of day, season and topography (Berger, 1993; County Government of Makueni, 2013; Gikaba et al., 2014).

Makueni County is predominantly inhabited by agropastoralists, while Kajiado County is mainly and traditionally occupied by pastoralists (Gikaba et al., 2014; Mganga et al., 2013). While livestock production is the major land use practice and economic activity in the two Counties (Mganga et al., 2013), small-holder subsistence farming is also practiced but highly dependent on rainfall (Amwata et al., 2015).

\section{Research design and data collection}

The target population for the study included fodder producers and their groups, traders, relevant national and county governments, other technical service producers and non-governmental organizations.

Data was collected through a participatory tool known as NetMap, which was developed by the International Food Policy Research Institute (IFPRI) for examining actors and their roles, linkages, influences and goals (Waale, 2008; Puri et al., 2017). The NetMap tool was chosen for this study as it is an interview-based mapping approach that lets people understand, visualize, discuss and improve conditions in which various different players with diverse influence levels have the ability to influence outcomes (Puri et al., 2017). Representatives of various stakeholders in the fodder value chain landscape were identified and engaged in identifying and mapping actors and institutions involved in fodder production and marketing, their roles, influence in decision making and interactions with regards to flow and provision of training and technical information on market, as well as funding and lines of authority.

Data was collected in the form of group interviews as guided by these four questions; (i) which stakeholders are involved in fodder production and marketing in the southern rangelands of Kenya? (ii) what roles do they play in the production and marketing practices? (iii) how do they interact? (iv) how do they influence decision making in relation to these practices?

A list of potential participants, groups of people or organizations presumed to be knowledgeable or experienced in fodder production and marketing was developed. The research team contacted those identified as knowledgeable and a list of potential participants for group discussion was developed through snowballing. The final list of 30 potential participants was reviewed to ensure that participants were representatives of all-important sectors. These identified participants were contacted through email or telephone call and officially invited for the stakeholder mapping workshops.

An actor who had an effect on allocation of resources was defined as "an actor influential in 'shaping' decisions" and this was related to the lines of authority. Flow of information and linkages were defined as a formal exchange of technical support (training, technical guides, equipment, information, research evidence, routine data or field experience/case studies). Funding links were defined as exchange of funds or in-kind support related to fodder production and marketing such as provision of free start up seed to the farmers.

Review of literature was done to gather information on fodder production and marketing practices in Kenya. These were obtained from published peer reviewed papers, research and development reports, donor reports about various aspects of fodder production and marketing in Kenya, institutional reports (research and development, including NGOs), academic theses, government (national and county) agricultural and development reports, webbased data sources, national census publications, among 


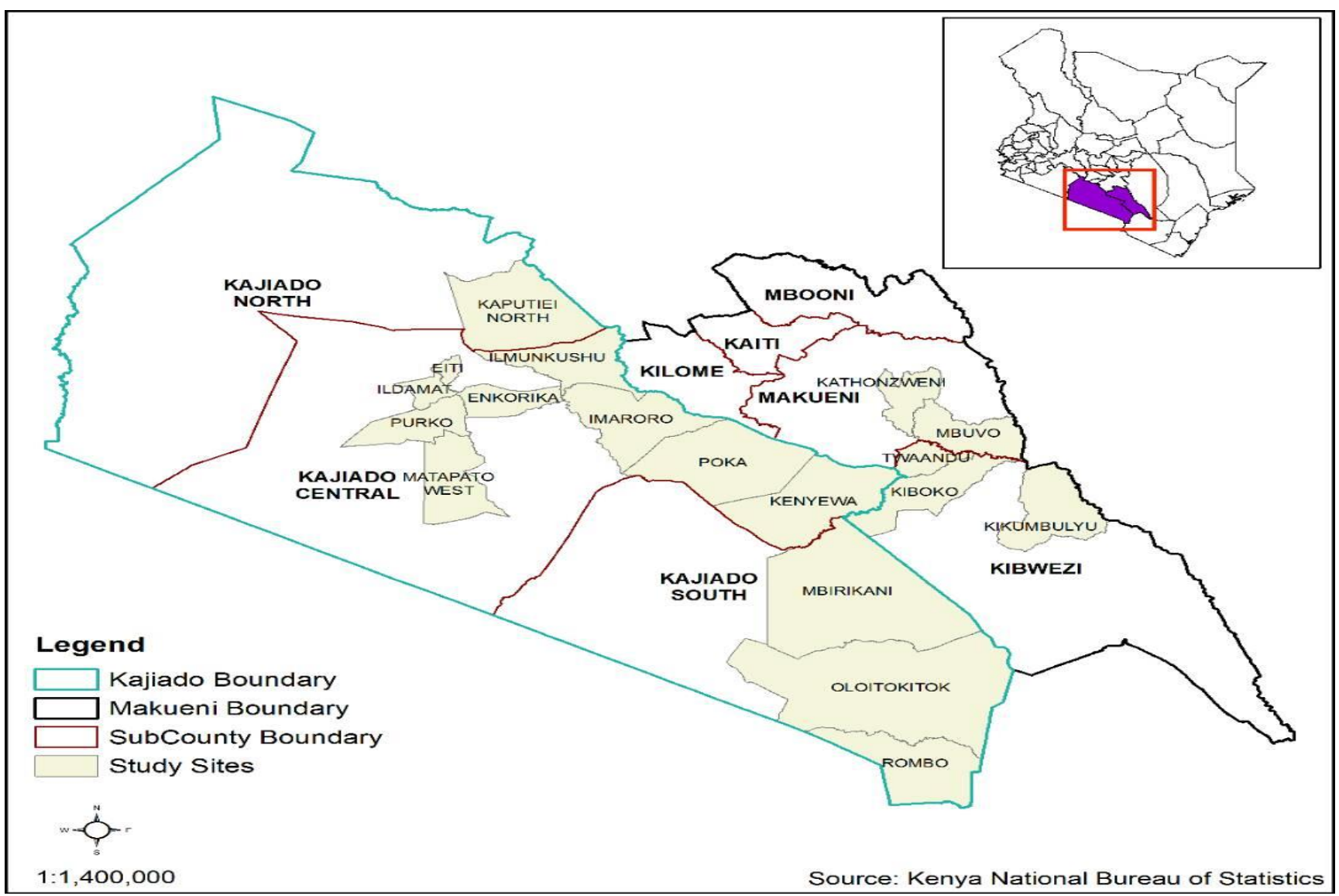

Figure 1. Map of Makueni and Kajiado Counties.

others.

Firstly, discussion was held with the groups regarding the stakeholders that may influence fodder production and marketing landscape. Subsequently, a list of likely actors was developed and placed into a blank NetMap sheet. Then, discussion was held of what roles each of these stakeholders play in the fodder value chain, how they interact with each other in relation to provision of training and flow of technical information, funding and lines of authority including direction of interaction (who to whom). A blank NetMap sheet was used to draw the interaction and direction using different colors for flow of information, funding and lines of authority. Next was to visualize the level of influence of each stakeholders against another, which was done through pairwise analysis where each stakeholder was compared to each other by asking who is more important than the other in relation to research and training, market and input information, as well as provision of funding as key important aspects of fodder production and marketing.

Key challenges of group interview as data collection methodology is to make sense of massive amounts of data, reduce the volume to valuable information, identify significant patterns and constructing a framework to communicate the essence of what the data reveals. Certain biases arose throughout the process including consistency, error and reference biases. Such biases were avoided by devising the interview guide neutrally with clear definitions of terminologies used to address the research questions. Sampling bias was addressed by including respondents from all segments of stakeholders including farmer groups, researchers, development partners, and government bodies.

\section{Data analysis}

Data was triangulated and collated by cross referencing both the qualitative and quantitative data. Quantitative data was entered into excel sheet for analysis. NetMaps were subjected to quantitative analysis using Organizational Risk Analysis (ORA) tool in Social Network Analysis (SNA) to map, as well as measure relationships and influences of stakeholders and examine relative positions. The ORA tool was used to develop the map of stakeholders and direction of their influences (Waale, 
2008; Puri et al., 2017).

\section{Network measures of social network analysis}

Quantitative analysis was also conducted in ORA to indicate the position and importance of various stakeholders in the fodder production and marketing systems by taking the following SNA measures: capability; in-degree, out-degree and total-degree centralities; centrality betweenness; closeness centrality; information centrality and cognitive demand. These measurements have been widely used in social studies to indicate roles and positions of stakeholders in a social network (Uddin et al., 2017).

\section{RESULTS AND DISCUSSION}

\section{Netmap of stakeholders in fodder value chain in the ASALs of Kenya}

Table 1 presents key actors in the fodder value chain and various roles they play in the chain. They were categorized into six major groups including: Kenya Agricultural and Livestock Research Organization (KALRO); County governments (through extension officers); Community Based Organizations (CBOs); Non-governmental Organizations (NGOs); individual fodder producers and traders. Various stakeholders provide different services and at different scales, which defines their ability to influence the flow of information and resources and therefore their positions and ability to influence decision making in the value chain.

Figure 2 presents map of the stakeholders in the fodder value chain in the study areas. These stakeholders were linked up through the flow of funding, research and training (technical support) and market information.

\section{Capability}

This computes the number of connections for each entity, thus evaluating the capability of an entity to perform tasks. For the most connected entity, this value tends to 1 and tends towards 0 for the least connected node (Carley et al., 2008). KALRO, CBOs and NGOs indicated the highest number of connections (Figures 2 and 3). This indicates that they have the highest ability to perform their various tasks in the fodder value chain including capacity building, provision of financial and technical support as well as dissemination of information on production and marketing as indicated in Table 1. This implies that they are playing key roles in influencing adoption, profitability and sustainability of fodder production technologies in the ASALs of Kenya. The county government also showed high score in relation to their ability to perform their duties in the value chain. These findings corroborate those of Omollo et al. (2017) who had documented that KALRO and CBOs are critically important for adoption and upscaling fodder production as an adaptation strategy among the pastoral and agro-pastoral communities in Kenya.

\section{In-degree centrality}

The in-degree centrality shows the tendency of a particular actor to receive inputs from other actors in the network thus measuring the receptivity or popularity of the actor (Puri et al., 2017). Interestingly, the quantitative analysis indicates that KALRO, CBOs, NGOs and traders have the highest in-degree while individual fodder producers in the study areas have the lowest in-degree centrality (Figure 4). This implies that fodder farmers at individual levels received minimal financial and technical support from other stakeholders in the value chain. On the other hand, fodder farmers who operate under the $\mathrm{CBO}$ s were found to receive substantial support from other actors in the value chain, which could also explain their high capability as expressed in Figure 3. Generally, past studies have indicated that collective action which comes as a result of working together through organized groups (CBOs) creates more advantages to the farmers than operating as individuals especially among the smallholder farmers in the developing world. They have been used effectively by small-scale producers to enhance access to input and output market, increase information access and profitability (Sally, 2013; Gyau et al., 2014).

\section{Out-degree centrality}

Out-degree centrality measures the tendency of an actor to make choices in terms of creating connections with other actors as well as its propensity to provide inputs to other actors in the network. It measures the expansiveness or activity of an actor in a network (Wasserman and Faust, 1994; Puri et al., 2017). A high out-degree centrality for an actor in the network indicates that he/she influences other actors through his/her technical and funding support. In this study, KALRO and CBOs were found to be the primary influencers with respect to funding and capacity building and other technical support followed with NGOs (Figure 5). They are key in disseminating fodder farming technologies. Individual farmers and traders had the least influence in relation to providing inputs and services to other actors in the value chain. This implies that the decision taken by individual fodder farmers are highly influenced by KALRO, $\mathrm{CBOs}$ and NGOs. Higher influences of organizations compared to individual farmers and traders could be attributed to their stronger financial and technical strengths 
Table 1. Stakeholders in fodder production and marketing chain and their roles.

\begin{tabular}{lll}
\hline Stakeholders & Roles \\
\hline KALRO & 1. & Capacity building - training producers on fodder production, soil and water \\
& conservation practices and hay and seed handling and storage
\end{tabular}

which allows them to be more effective and efficient in undertaking their roles, making them more influential (Madhani, 2009).

\section{Centrality: Total degree}

Total degree centrality is one of the key measures of SNA and Dynamic Network Analysis (Wasserman and Faust, 1994 (p. 199). It indicates the relative number of direct connections a stakeholder might have in a network. The higher the score the more an actor is likely to receive and potentially pass on critical information that flows through the network. CBOs indicated the highest total degree centrality implying that they have the highest chance of receiving and disseminating information on fodder production and marketing in the study areas (Figure 6). This could be attributed to the fact that most NGOs and government bodies prefer to work with farmer groups rather than individual farmers, which provide an easy entry point to reaching larger number of farmers in the community (Omollo et al., 2017). KALRO and NGOs also showed high positions in terms of receiving and sharing information on fodder farming in the study areas. Figure 6 further showed that individual fodder producers have the least total degree centrality, thus low ability to receive and share information and inputs to other actors in the fodder value chain in the study areas. Collective action through CBOs has been identified as a powerful tool that enables smallholder farmers to overcome challenges affecting their capabilities to produce and access market, it particularly enhances access to technical and financial support from service providers including extension officers, NGOs amongst others (Markelova et al., 2009).

\section{Centrality: Betweenness}

Betweenness tells which node is the most connected to other parts of a network. For example, it can tel I which 


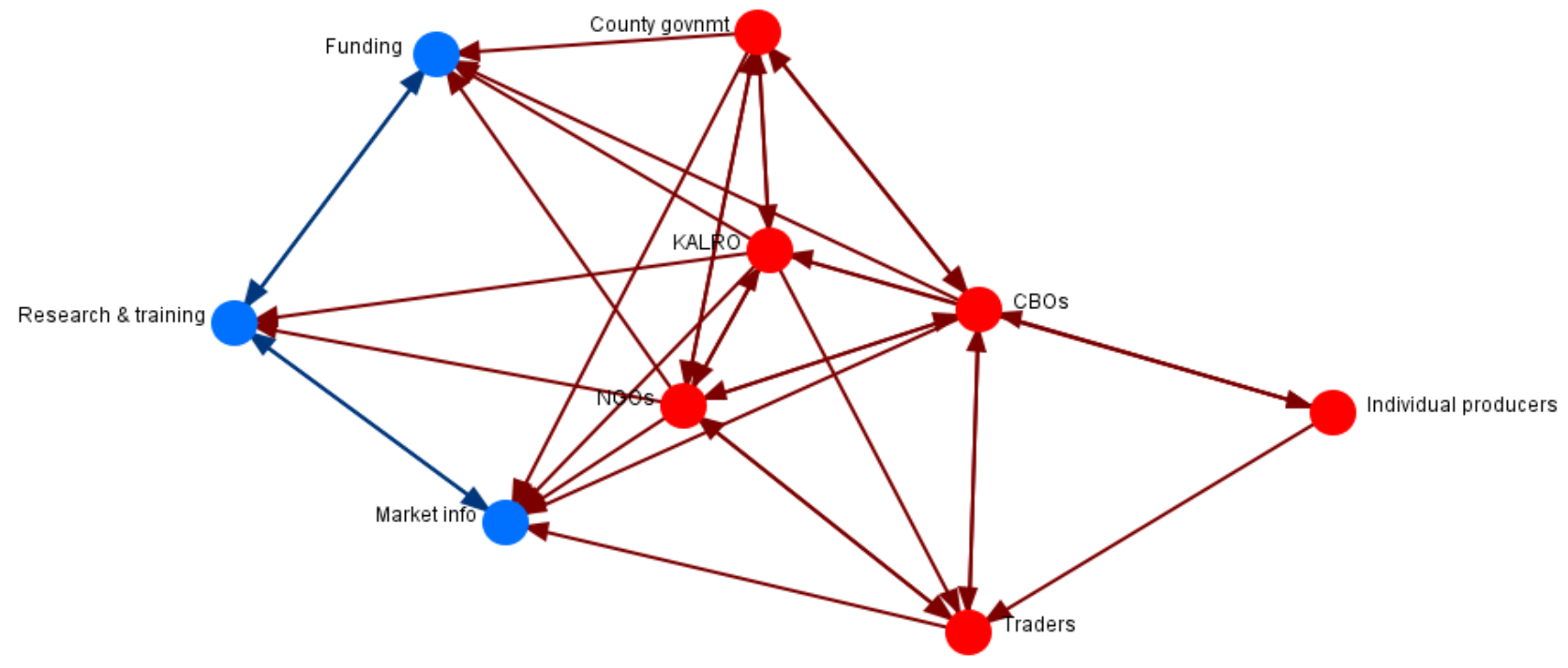

Blue $=$ Stakeholder

Red $=$ Role

powered by ORA

Figure 2. Visual illustration of key stakeholders in fodder value chain in the study area and their key roles.

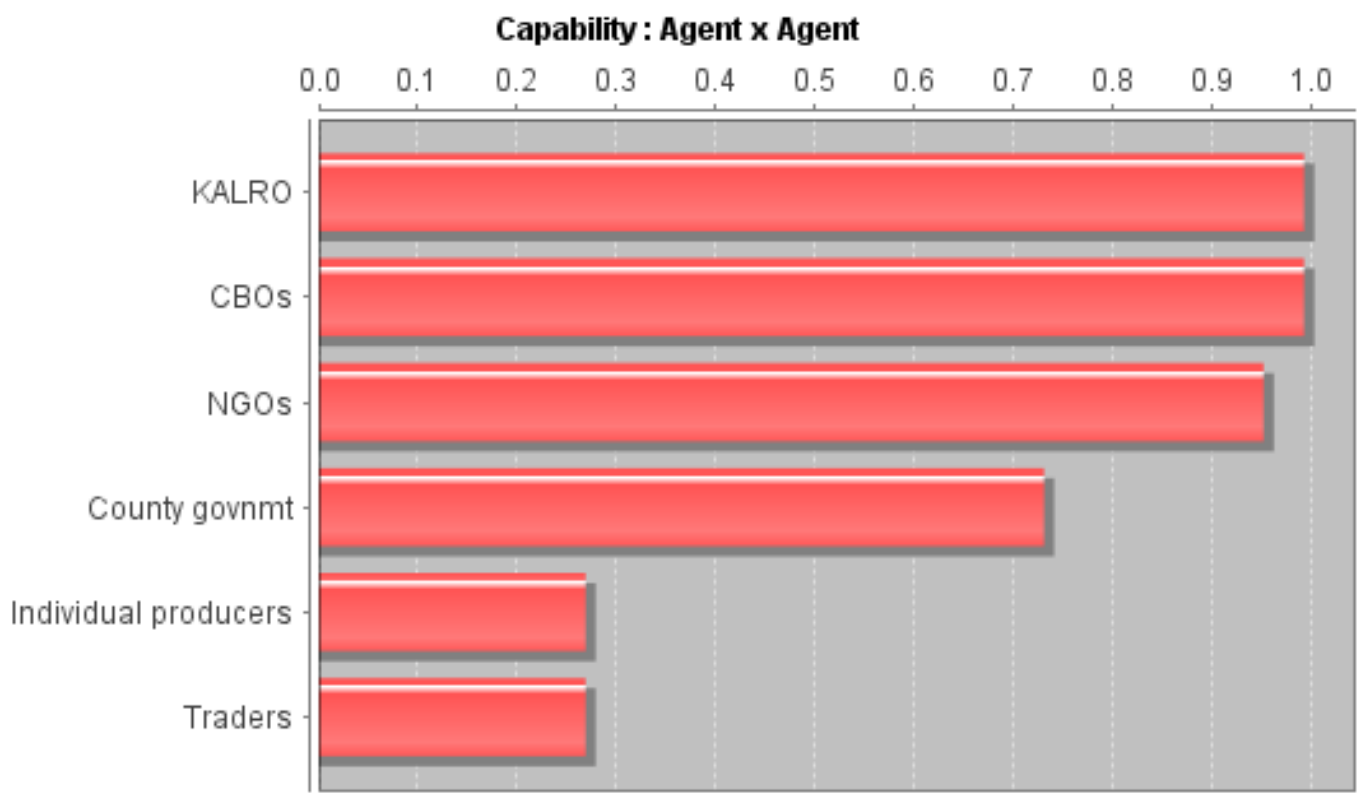

Figure 3. Capability of stakeholders in fodder production and marketing social network.

person in a network is the most central to the network as a whole. Betweenness measures the number of times that connections pass through a single individual. It indicates the extent to which an actor controls the flow of information between actors by its position in the network (Wasserman and Faust, 1994). Actors that occur on many shortest 


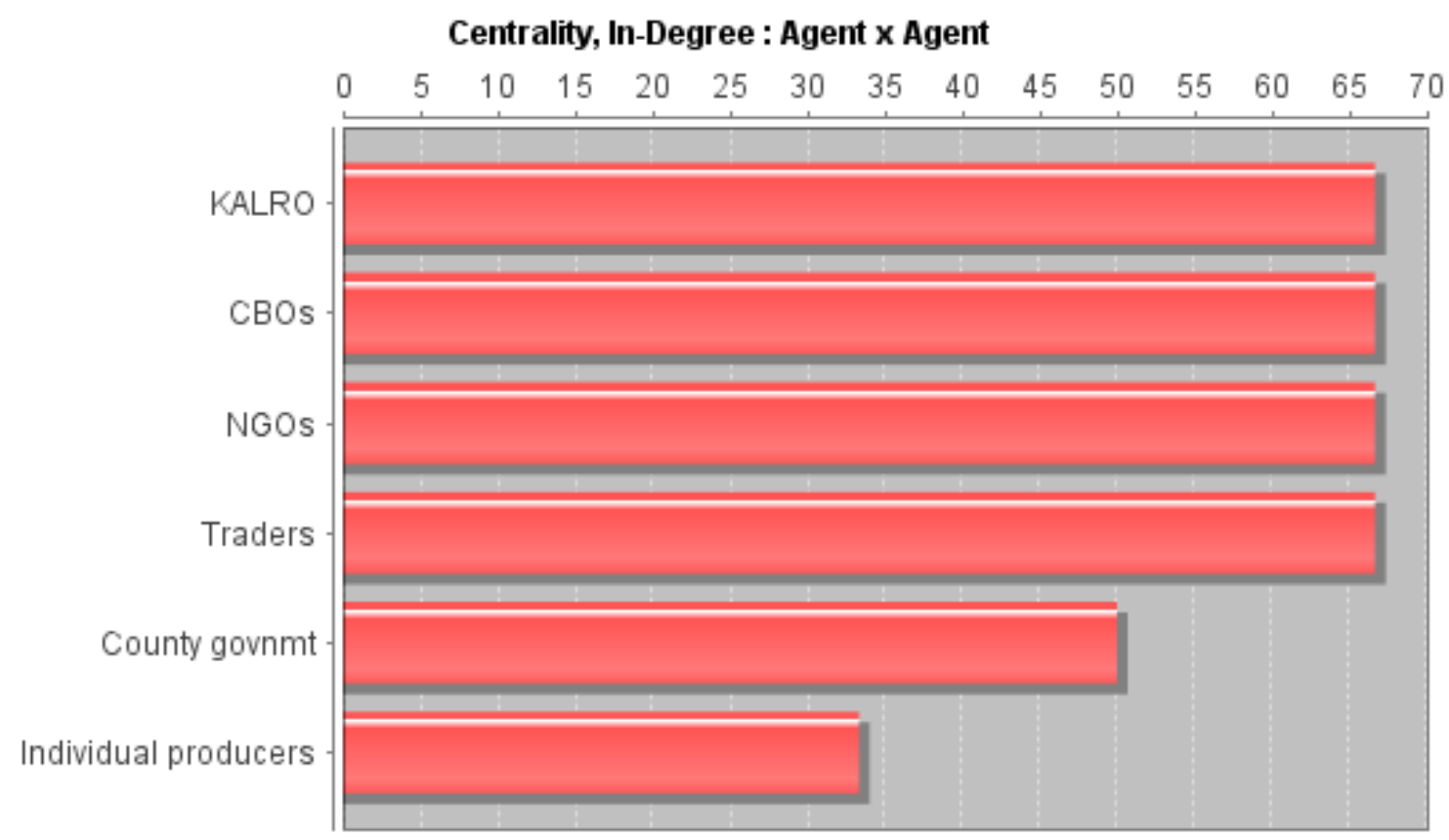

Figure 4. In-degree centrality of stakeholders in fodder production social network.

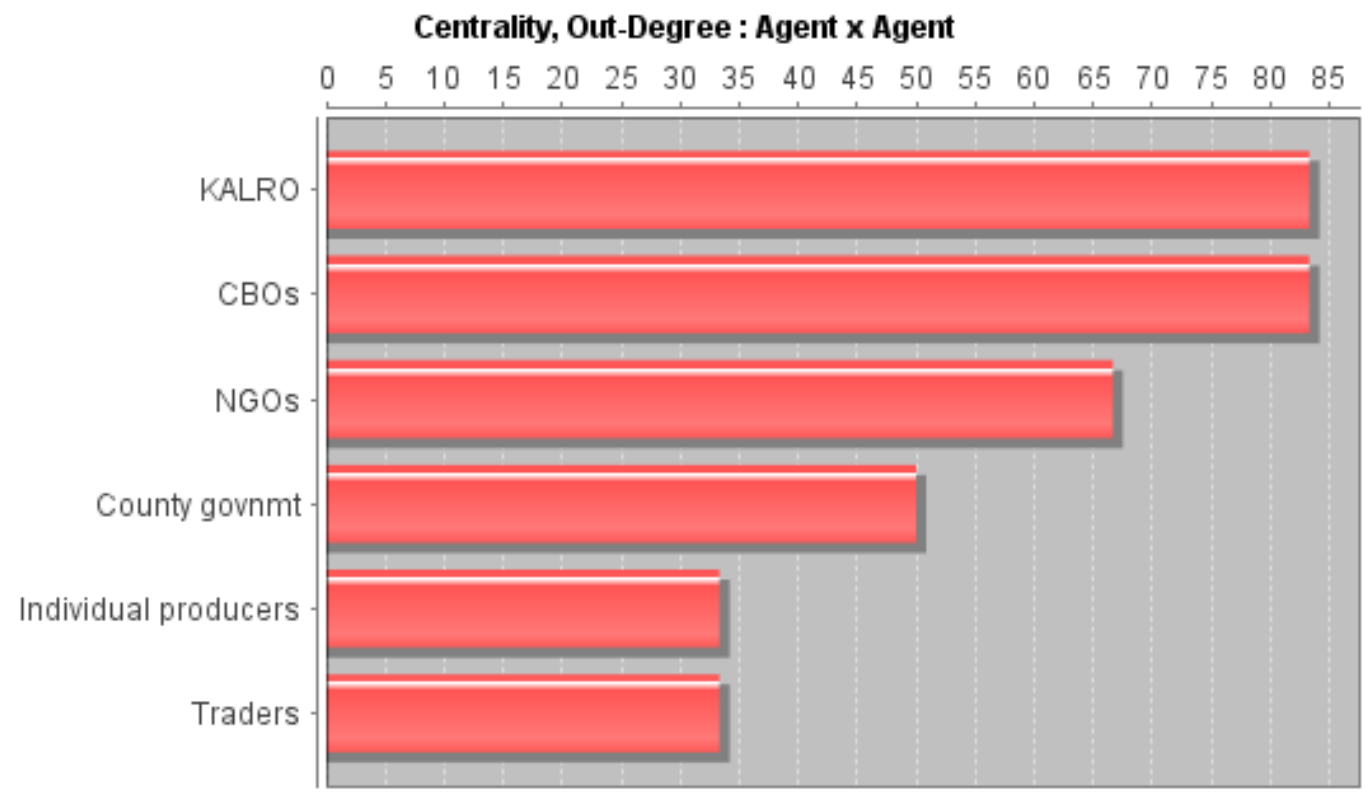

Figure 5. Out-degree centrality of stakeholders in fodder production social network.

paths among other actors have highest betweenness value. By the virtue of its strategic position in the network, $\mathrm{CBOs}$ indicated the highest betweenness (Figure 7) implying that they had the largest number of connections among the stakeholders in the fodder value chain. In this relation, most fodder producers - individuals and group obtain much information from the CBOs, which are also the main entry point for extension officers, NGOs and other service providers in sharing information on fodder production technologies and related technical support. This is attributable to the fact that most government and development agencies prefer to work with collective action 


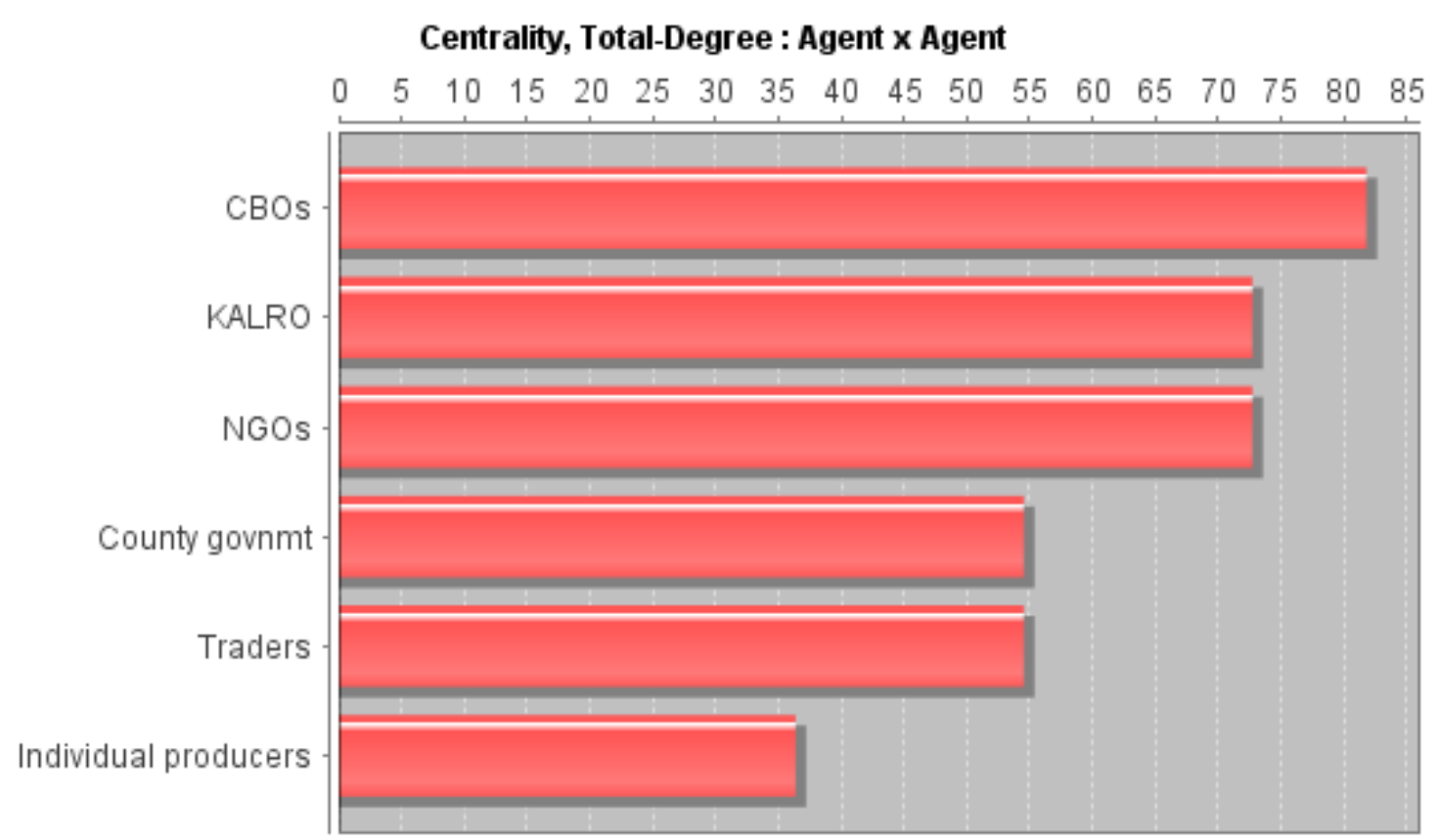

Figure 6. Total-degree centrality of stakeholders in fodder production social network.

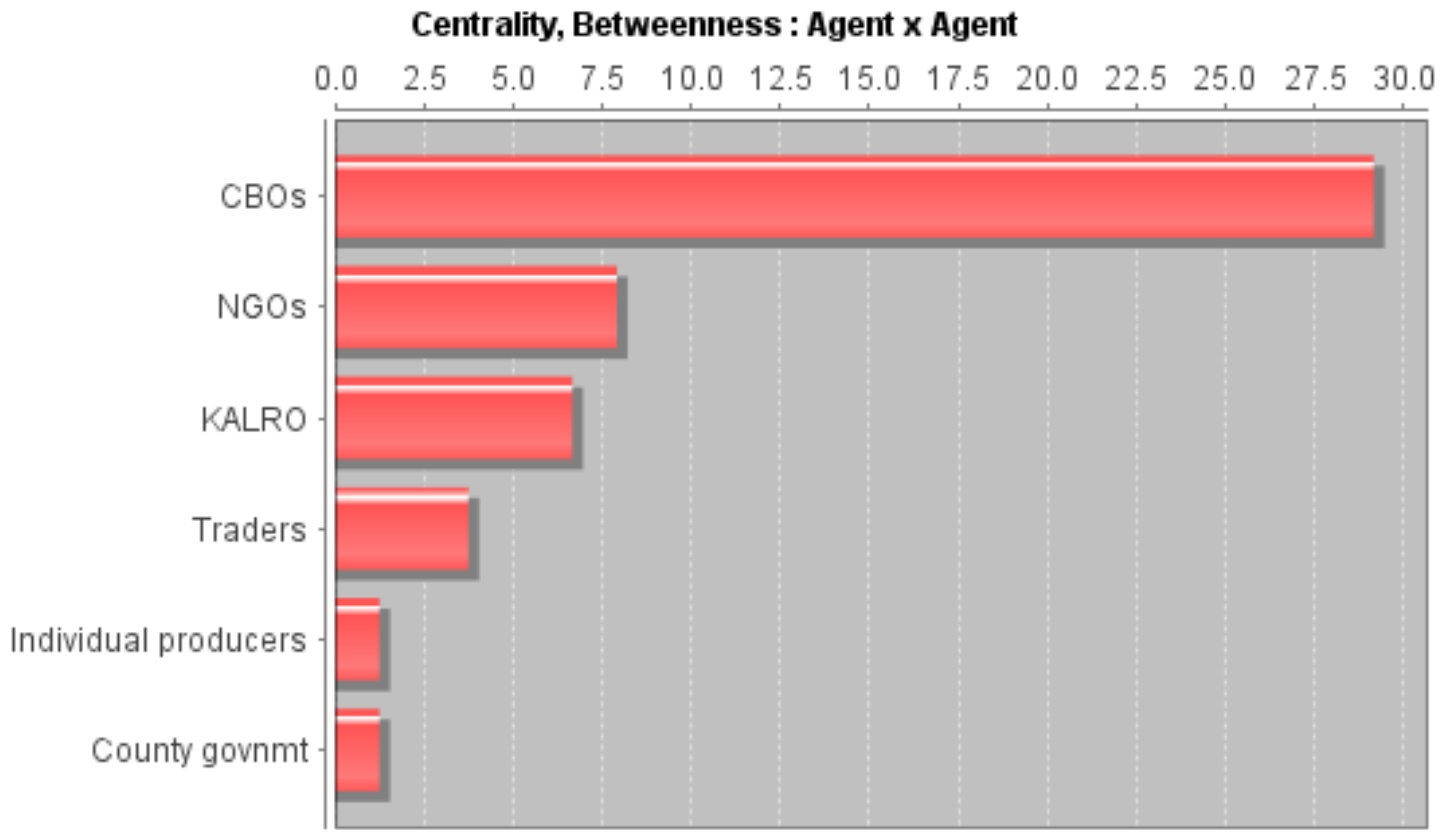

Figure 7. Betweenness centrality of stakeholders in fodder production social network.

groups such as CBOs which enables wide community outreach and create more impacts particularly among smallholder farmers in the community (Omollo et al., 2017; Markelova et al., 2009).

\section{Centrality: Closeness}

As indicated by Wasserman and Faust (1994), closeness measures the path length from one person to another in a 


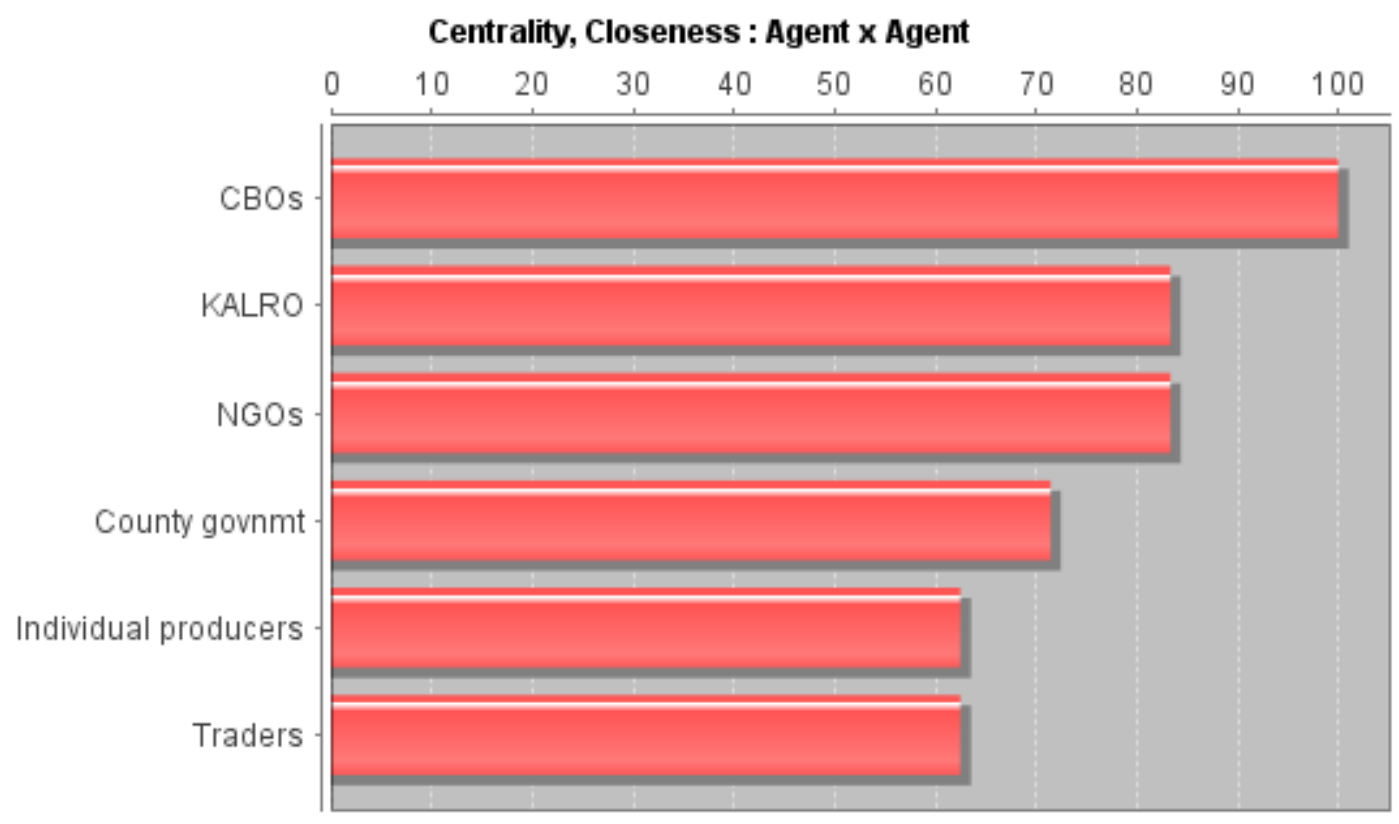

Figure 8. Closeness of stakeholders in fodder production social network.

network - reachability and level of connectivity of an actor from the other actors. For example, it tells which person is central to an organization. Moreover, closeness reveals how long it takes information to spread from one individual to others in the network. High scoring individuals in Closeness have the shortest paths to all others in the network. It would follow that such individuals could monitor the information flow in an organization better than most others that have a lesser closeness value. The ones with the highest value in this measure will often have the best picture of what is happening in the network as a whole (Freeman, 1979; Carley et al., 2008). Results of this study indicated that $\mathrm{CBO}$ s have the highest connectedness with the rest of the actors in the network, implying that they are the most accessible to the rest of the actors in the network (Figure 8). They also enjoy the ease of reaching other actors if need be. This could be attributed to the strategic location in the network compelling of other chain actors to link up and work together with them. KALRO and NGOs showed high closeness centrality, which could be due to their key roles in providing funding and technical support to smallholder fodder farmers in the study areas. The study found that traders and individual fodder producers have the lowest connectedness with longest accessibility to other stakeholders in the fodder value chain. They receive limited or no financial or technical support from other actors in the network.

\section{Information centrality}

This calculates the Stephenson and Zelen information centrality measure for each actor. Information centrality is a network metric that accounts for indirect and shortest (geodesic) paths among entities. Information centrality is similar to betweenness, except that betweenness considers only shortest paths geodesics, whereas information centrality also considers more circuitous paths weighted by the inverse of the path length (the number of links along the path). Actors with high information centrality do not only have higher likelihood of obtaining more information but also get it faster (Wasserman and Faust, 1994 (p. 195); Carley et al., 2008). In this study, KALRO and CBOs showed the highest information centrality followed by NGOs (Figure 9). This implies that they can easily access information and even faster in relation to fodder production and marketing, which in turn influences the decision they make in relation to fodder farming and marketing. Individual producers who showed the lowest information centrality were limited in their ability to access information thus limiting their decision-making abilities.

\section{Cognitive demand}

Cognitive demand measures the total amount of effort expended by each agent to do its tasks. Individuals who are high in cognitive demand value are emergent leaders. Removal of these individuals tends to be quite disruptive to networks. In this study, KALRO and NGOs showed the highest cognitive demand followed by CBOs, indicating that they are critically important in the fodder value chain (Figure 10). While KALRO and NGOs are the top providers of funding and technical support to smallholder fodder producers in the drylands of Kenya, CBOs are key in 


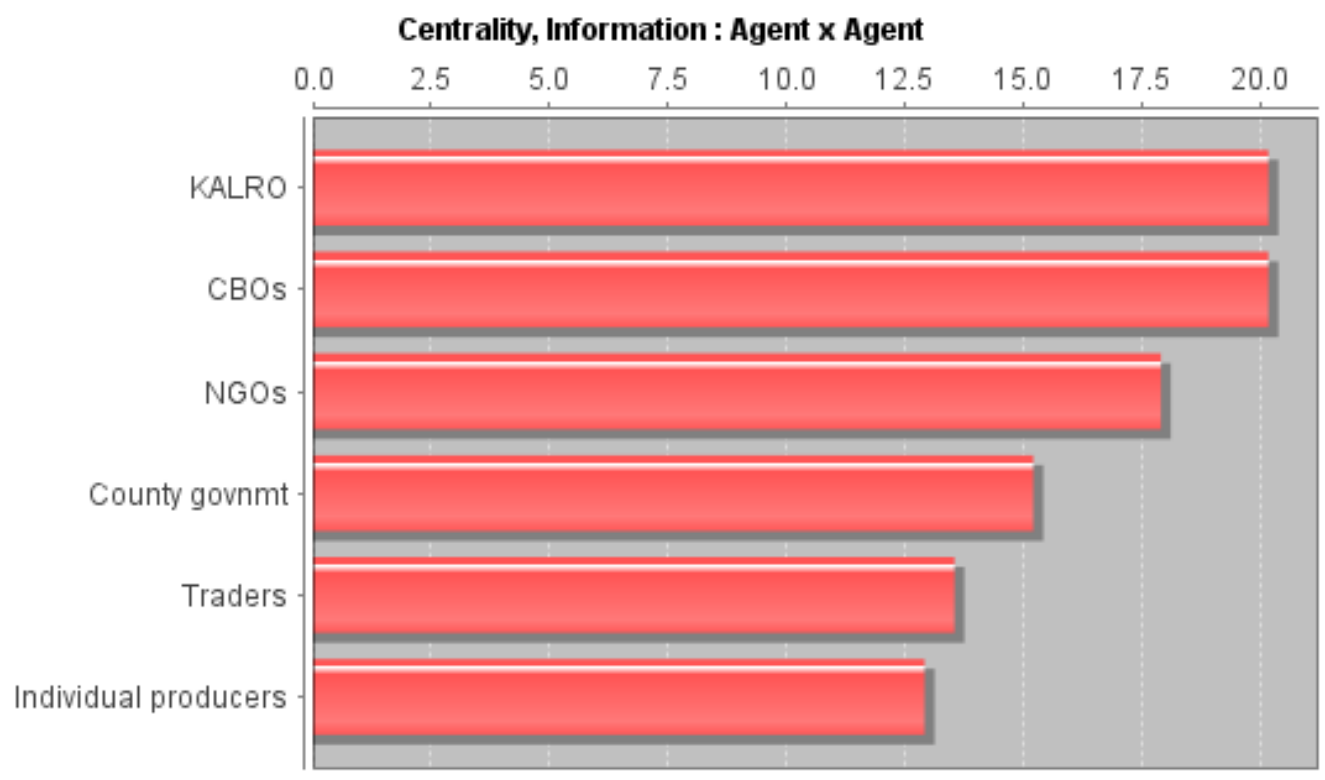

Figure 9. Information Centrality of stakeholders in fodder production social network.

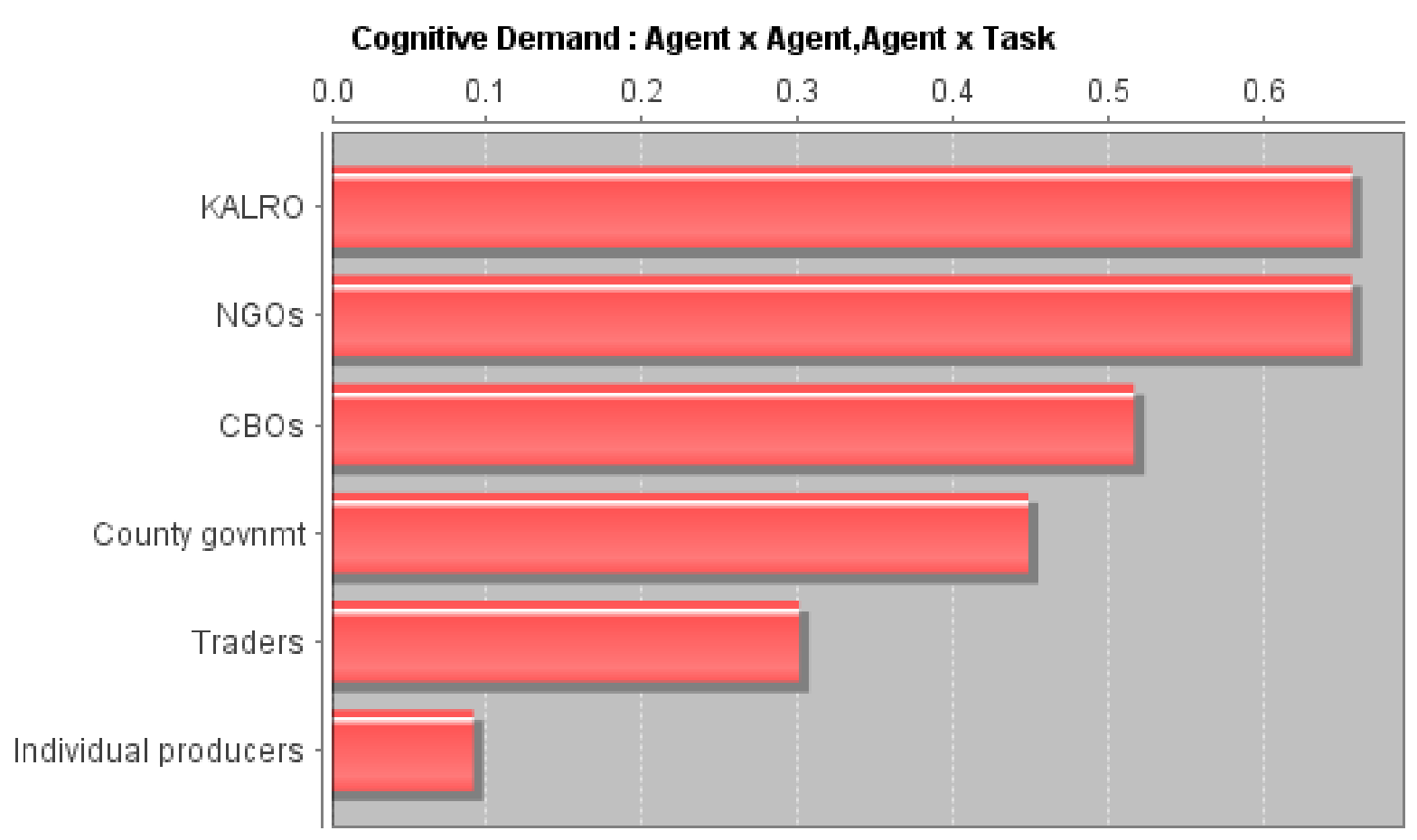

Figure 10. Cognitive demand of stakeholders in fodder production social network.

enhancing adoption and upscaling of fodder production practices among pastoral and agro-pastoral communities in Kenya. KALRO and NGOs also provide markets for hay and grass seed, attributing to their high cognitive demand in the fodder production network. Individual producers showed the least cognitive demand which could be explained by low or independence of other actors in the network on them. 


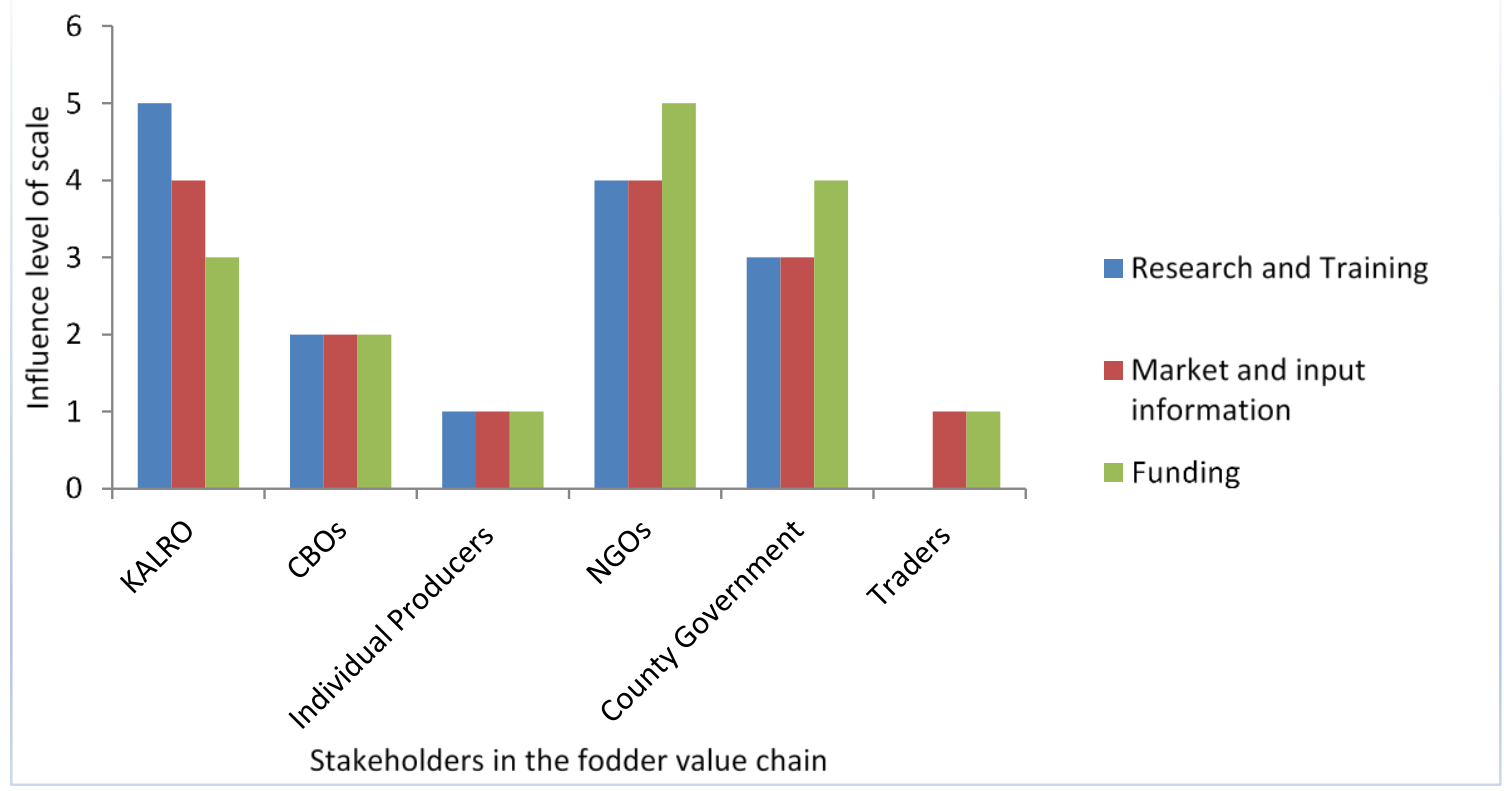

Figure 11. Average influence levels of stakeholders on key roles: research and training, market and input information and funding.

\section{Average influence levels of stakeholders on key roles: research and training, market and input information and funding}

Each of the six categories of stakeholders was also analyzed in relation to their level of influence on the research and training; provision of market and input information as well as funding and results presented in Figure 11.

As a research institution, KALRO showed the highest contribution to new knowledge on fodder production through research (Figure 11). Some of these include reseeding, enclosure and water harvesting technologies, which have greatly promoted adoption of fodder production among pastoral and agro-pastoral communities in Kenya. They also link producers to the market for hay and grass seeds. NGOs key role was found to be provision of funding (in-kind) mainly to fodder producer groups (CBOs). Of the three key roles, CBOs were found to play equal roles in funding their activities (through table banking), enhancing market access as a team and capacity building through peer to peer learning. County governments were also found to play more roles in funding fodder production among the community members than the other two sets of roles for which the county governments showed equal contributions. Hay and grass seed traders only provided limited financial and information regarding inputs and marketing through their marketing interactions with the producers. These findings corroborate with those of Omollo et al (2017) and Lugusa et al. (2016) who on their different research work in the fodder value chain in the ASALs of Kenya indicated that KALRO was the key stakeholder in fodder value chain - it developed and disseminated fodder production practices among various producers, particularly smallholder fodder producers. NGOs also have been found to play key roles in enhancing adoption of fodder production among communities in Kenya, particularly though providing startup grass seed and training of production practices (Omollo et al., 2017).

\section{Conclusion}

Varied stakeholders play multiple roles in the fodder value chain and this determine their position and influence in decision making along the chain in the southern rangelands of Kenya. Most influential stakeholders include KALRO, NGOs and CBOs as they determine access to information, technical and funding resources and markets; thus, key in upscaling, out-scaling and commercialization of fodder production among smallholder producers in the ASALs of southern Kenya. Working in groups (CBOs) empowers fodder producers - enables them to easily access technical support and information and interact with other stakeholders in fodder value chain. Efforts for enhancing fodder production and its benefits would target to provide more technical support and capacity building to the CBOs due to their centrality and strategic position in the network making them the main stakeholder that would 
enhance adoption of fodder production practices and associated benefits. It may also target individually operating producers to create awareness of the importance of joining producer groups (CBOs) to access benefits that government and NGOs offer to the farmers through their collective action groups. Key stakeholders (service providers) in fodder value chain need to work in partnerships and in a coordinated approach in order to harmonize their contributions and avoid duplications of efforts towards enhancing commercialization of fodder production among the smallholder producers. Also, there is need for investment in innovating and developing models that will not only enable easy access to information but also facilitate participatory stakeholder engagement at all levels of fodder value chain.

\section{ACKNOWLEDGEMENTS}

We thank the International Development Research Centre (IDRC) through the African Climate Change Leadership Program (AfriCLP) for funding this research work.

\section{CONFLICT OF INTEREST}

The authors declare no conflict of interest.

\section{REFERENCES}

Africa Sustainable Development Report (ASDR) (2017). Tracking Progress on Agenda 2063 and the Sustainable Development Goals.

Amwata, D. A., Nyariki, D. M., \& Musimba, N. R. (2015). Factors influencing pastoral and agropastoral household vulnerability to food insecurity in the drylands of Kenya: A case study of Kajiado and Makueni Counties. Journal of International Development, 28(5), 771-787.

Anderson, K., \& Masters, W. A. (Eds.). (2009). Distortions to agricultural incentives in Africa. World Bank Publications.

Berger, D. J. (1993). Wildlife extension: participatory conservation by the Maasai of Kenya.

Carley, K. M., Columbus, D., DeReno, M., Reminga, J., \& Moon, I. C. (2008). ORA User's Guide 2008. Center for the Computational Analysis of Social and Organizational Systems. CASOS Technical Report. Institute for Software Research, School of Computer Science, Carnegie Mellon University, Pittsburgh, PA 15213.

Central Bureau of Statistics (CBS) (2009). The 2009 Population Census. Government Printer: Nairobi, Kenya.

County Government of Makueni (2013). County First Integrated Development. 2013-2017. Article retrieved August 22, 2016 from:

https://www.kenyampya.com/userfiles/Makueni\%20CIDP\%20 sept2013(1).pdf.

Dolan, R., Defoer, T., \& Paultor, G. (2004). Final Feasibility Report. Kenya Arid and Semi-Arid Lands Research Programme. Kenya Agricultural Research Institute. Kenya.
Freeman, L. C. (1979). Centrality in Social Networks I: Conceptual Clarification. Social Networks, 1, 215-239.

Gikaba, J. M., Muthoni, K. S., \& Bebe, B. O. (2014). Influence of Drought Duration on Livestock Feeding Practices by Maasai Pastoralists in Kajiado County Kenya. International Journal of Innovation and Applied Studies, 8(1), 225-231.

Gyau, A., Franzel, S., Chiatoh, M., Nimino, G., \& Owusu, K. (2014). Collective action to improve market access for smallholder producers of agroforestry products: key lessons learned with insights from Cameroon's experience. Current Opinion in Environmental Sustainability, 6, 68-72.

Huho, J. M., \& Mugalavai, E. M. (2010). The effects of droughts on food security in Kenya. International Journal of Climate Change: Impacts and Responses, 2(2), 61-72.

Intergovernmental Panel on Climate Change (IPCC) (2014). Summary for policy makers. In: Climate Change 2014: Impacts, Adaptation, and Vulnerability. Part A: Global and Sectoral Aspects. Contribution of Working Group II to the Fifth Assessment Report of the Intergovernmental Panel on Climate Change. Field, C. B., Barros, V. R., Dokken, D. J., Mach, K. J., Mastrandrea, M. D., Bilir, T. E., Chatterjee, M., Ebi, K. L., Estrada, Y .O., Genova R. C., Girma, B., Kissel, E. S., Levy, A. N., MacCracken, S., Mastrandrea, P. R. \& White, L. L. (eds.)]. Cambridge University Press, Cambridge, United Kingdom and New York, NY, USA, Pp. 1-32.

Kidake, B. K., Manyeki, J. K., Kubasu, D., \& Mnene, W. N. (2016). Promotion of range fodder and fodder production among the pastoral and agro-pastoral communities in Kenyan rangelands: Experiences and lessons learnt. Livestock Research for Rural Development, 28(8).

http://www.Irrd.org//rrd28/8/kida28151.html.

Kiveu, M., \& Ofafa, G. (2013). Enhancing market access in Kenyan SMEs using ICT. Global Business and Economics Research Journal, 2(9), 29-46.

Koech, O. K., Kinuthia, R. N., Karuku, G. N., Mureithi, S. M., \& Wanjogu, R. (2016). Field curing methods and storage duration affect the quality of hay from six rangeland grass species in Kenya. Ecological Processes, 5(3), 1-6. Retrieved 2nd March, 2017 from http://ecologicalprocesses.springeropen.com/articles/10.1186 /s13717-016-0048-2.

Lugusa, O. K., Wasonga, V. O., Yazan, A. E., \& Crane, T. A. (2016). Value chain analysis of grass seeds in the drylands of Baringo County, Kenya: A producers' perspective. Pastoralism: Research, Policy and Practice, 6(6). Retrieved from

https://pastoralismjournal.springeropen.com/articles/10.1186/ s13570-016-0053-1

Macharia, P. N., Kinyamario, J. I., Ekaya, W. N., Gachene, C. K. K., \& Mureithi, J. G. (2015). Improvement of traditional fodder preservation areas with forage legumes in semi-arid rangelands of Kajiado District. Retrieved 4th March, 2016 from https://www.researchgate.net/publication/265945731.

Madhani, P. M. (2009). Resource based view (RBV) of competitive advantages: Importance, issues and implications. KHOJ Journal of Indian Management Research and Practices, 1(2), 2-12.

Manyeki, J. K., Kirwa, E. C., Ogillo, P. B., Mnene, W. N., Kimitei, R., Mosu, A., \& Ngetich, R. (2015). Economic analysis of natural pasture rehabilitation through reseeding in the southern rangelands of Kenya. Livestock Res. for Rural Development, 27(3), 49-61. 
Mapfumo, P., Adjei-Nsiah, S., Mtambanengwe, F., Chikowo, R., \& Giller, K. E. (2013). Participatory action research (PAR) as an entry point for supporting climate change adaptation by smallholder farmers in Africa. Environmental Development, 5, 6-22.

Markelova, H., Meinzen-Dick, R., Hellin, J. and Dohrn, S. (2009). Collective action for smallholder market access. Food policy, 34(1), 1-7.

Mattern, M., \& Michael, T. (2015). Designing Financial Services for Smallholder Families. Research \& Analysis Publication. Perspective 1. Washington, D.C.: CGAP. https://www.cgap.org/research/publication/designing-digitalfinancial-services-smallholder-families.

Mganga, K. Z., Musimba, N. K. R., Nyariki, D. M., Nyangito, M. M., \& Mwang'ombe, A. W. (2015). The choice of grass species to combat desertification in semi-arid Kenyan rangelands is greatly influenced by their forage value for livestock. Grass and Forage Science, 70(1), 161-167.

Mnene, W. N., Wandera, F. P., \& Lebbie, S. H. (1999). Arresting environmental degradation through accelerated on site soil sedimentation and re-vegetation using micro-catchment and re-seeding. In: Proc. Agricultural Research and Development for sustainable Resource Management and Increased Production. 6th KARI Scientific Conference, 9-13th November 1998. Nairobi, Kenya.

Omollo, E. O., Wasonga, O. V., Elhadi, M. Y., \& Mnene, W. N. (2018). Determinants of pastoral and agro-pastoral households' participation in fodder production in Makueni and Kajiado Counties, Kenya. Pastoralism, 8(1), 9.

Omollo, E. O., Wasonga, O. V., Elhadi, Y. A. M., \& Mnene, W. N. (2017). Grass seed value chain analysis in the Southern Kenya range lands of Makueni and Kajiado Counties. Conference paper. RUFORUM Working Document Series, 14(2), 645-651.
Puri, S., Sylvia, F., Amrita, P., Deepika, A., Abhay, G., Zahiruddin, Q. S., Archana P., Shahadat, U., \& Anne, M. T. (2017). Policy content and stakeholder network analysis for infant and young child feeding in India.

Sally, B. (2013). Women's collective action: unlocking the potential of agricultural markets. Oxfam research report. Oxfam International; 2013.

The Livestock Development Strategy for Africa (LiDeSA) 2015 2035 (2015). The Roadmap to a Successful Livestock Sector. Department of Rural Economy and Agriculture, African Union Commission, Nairobi, Kenya.

Uddin, S., Mahmood, H., Senarath, U., Zahiruddin, Q., Karn, S., Rasheed, S., \& Dibley, M. (2017). Analysis of stakeholders networks of infant and young child nutrition programmes in Sri Lanka, India, Nepal, Bangladesh and Pakistan. BMC public health, 17(2), 405.

Waale, D. (2008). Tracing Power and Influence in Networks: NetMap as a Tool for Research and Strategic Network Planning (Vol. 772). Intl Food Policy Res Inst.

Wairore, J. N., Mureithi, S. M., Wasonga, O. V., \& Nyberg, G. (2015). Enclosing the commons: reasons for the adoption and adaptation of enclosures in the arid and semi-arid rangelands of Chepareria, Kenya. SpringerPlus, 4(1), 595.

Wasserman, S., \& Faust, K. (1994). Social Network Analysis: Methods and Applications. Cambridge: University Press. 